\title{
Diversity of Macro-invertebrates with Respect to Selected Environmental Variables of Walawe River Upstream
}

\author{
H.P.S.U. Chandrarathna ${ }^{*}$, T. Priadarshana, H.B. Asanthi \\ Department of Limnology, University of Ruhuna, Sri Lanka \\ *surathsanda@gmail.com
}

\begin{abstract}
Benthic macro-invertebrates play an important role in aquatic community and many factors including environmental variables regulate their composition and community structure. The variation of community structure and diversity of macro-invertebrates in a selected part of Walawe River were studied with respect to variations of substrate characters, stream morphology, habitat availability and water quality. Four sampling sites were selected along the Walawe River, at Kalthota, before Kalthota irrigation dam. Water, substrate and macroinvertebrate samples were collected fortnightly during the dry period from September to November in 2014. Collectively 23 families, belongs to seven orders and two classes were identified. Principal Component Analysis showed that the studied environmental parameters such as temperature, $\mathrm{pH}$, conductivity, dissolved oxygen, total suspended solids, water velocity, stream discharge, the maximum particle size of the smallest $10 \%$ and $30 \%$ of the substrate samples and benthic organic matter, were more or less specific among sites and can be used to describe the habitats. Although Shannon Weiner's Diversity Index was not significantly different among sites, beta similarity index and family richness values showed that taxa composition is different among sites. Higher values of EPT index (total number of species of Ephemeroptera, Plecoptera and Trichoptera orders) indicates that the stream is in non-polluted condition because of the presence of many sensitive taxa in the stream benthos. Middle part of the selected portion of the stream has the most diverse morphological characters and environmental parameters, and consequently recorded the highest aquatic macro-invertebrate taxa. It was concluded that the cumulative effect of the studied environmental parameters affect the variation of community structure and diversity of macroinvertebrates.
\end{abstract}

Keywords: Aquatic macro-invertebrates, Diversity index, Stream substrate 